\title{
Doppler lidar observations of sensible heat flux and intercomparisons with a ground-based energy balance station and WRF model output
}

\author{
Jenny Clare Davis $^{1 *}$, Christopher G. Collier ${ }^{1}$, Fay Davies ${ }^{1}$, Guy N. Pearson ${ }^{1}$, Ralph \\ BURTON $^{2}$ and ANDREW RUSSELL ${ }^{3}$ \\ ${ }^{1}$ The University of Salford, Salford, Greater Manchester, UK \\ ${ }^{2}$ School of Earth and Environment, The University of Leeds, Leeds, UK \\ ${ }^{3}$ School of Earth, Atmospheric and Environmental Sciences, The University of Manchester, Manchester, UK
}

(Manuscript received September 9, 2008; in revised form February 12, 2009; accepted February 12, 2009)

\begin{abstract}
During the Convective and Orographically induced Precipitation Study (COPS), a scanning Doppler lidar was deployed at Achern, Baden-Wüttemberg, Germany from $13^{\text {th }}$ June to $16^{\text {th }}$ August 2007. Vertical velocity profiles ('rays') through the boundary layer were measured every 3 seconds with vertical profiles of horizontal wind velocity being derived from performing azimuth scans every 30 minutes. During Intense Observation Periods radiosondes were launched from the site. In this paper, a case study of convective boundary layer development on $15^{\text {th }}$ July 2007 is investigated. Estimates of eddy dissipation rate are made from the vertically pointing lidar data and used as one input to the velocity-temperature co-variance equation to estimate sensible heat flux. The sensible heat flux values calculated from Doppler lidar data are compared with a surface based energy balance station and output from the Weather Research and Forecasting (WRF) model.

\section{Zusammenfassung}

Während der Studie zu konvektiven und orographisch induzierten Niederschlägen (Convective and Orographically induced Precipitation Study - COPS) wurde das 1,5 $\mu \mathrm{m}$ scannende Doppler-Lidar der Organisation UFAM (Universities' Facility for Atmospheric Measurement) an seinem Messstandort in Achern, BadenWürttemberg, Deutschland vom 13. Juni bis zum 16. August 2007 von der Universität Salford, UK, betrieben. Vertikale Windgeschwindigkeitsprofile der atmosphärischen Grenzschicht wurden alle 3 Sekunden gemessen. Aus 30-minütigen Azimut-Scans wurden die Horizontalgeschwindigkeitsprofile abgeleitet. Während der intensiven Beobachtungsperioden wurden zusätzlich Radiosonden vom Messplatz gestartet. Im vorliegenden Artikel wird eine konvektive Fallstudie am 15. Juli 2007 näher untersucht. Vom vertikal gerichteten Lidar wird die Eddy-Dissipationsrate abgeschätzt. Sie wird in der Kovarianzgleichung zwischen Windgeschwindigkeit und Temperatur zur Abschätzung des fühlbaren Wärmeflusses verwendet. Die verwendeten Annahmen werden explizit erwähnt. Der für die verwendete Methode benötigte Grad der atmosphärischen Instabilität wird durch den Vergleich mit den Radiosondendaten bestätigt. Die abgeleiteten Ergebnisse stimmen gut mit den Daten der Energiebilanzstation und des WRF Modells überein.
\end{abstract}

\section{Introduction}

The Convective and Orographically-Induced Precipitation Study (COPS) field trial was conducted in the Black Forest region of Germany during the summer of 2007. Its aim was to advance the quality of forecasts of orographically-induced convective precipitation using extensive observations and modelling (COPS, 2007 ${ }^{1}$ ). The University of Salford own and operate a scanning $1.5 \mu \mathrm{m}$ Doppler lidar system, and were funded by the Universities' Facility for Atmospheric Measurement (UFAM) through the UK Natural Environment Research Council to participate in the project. The Doppler lidar was mounted in a mobile laboratory and has a full hemi-

\footnotetext{
*Corresponding author: Jenny Clare Davis, The University of Salford, Salford, Greater Manchester, M5 4WT, UK, e-mail: C.Davis@salford.ac.uk

${ }^{1}$ Convective and Orographically-Induced Precipitation Project 2007, available at www.cops2007.de
}

spheric scanning capability using a dual-mirror scanning system. Additionally, a 14 channel microwave radiometer and a Campbell Scientific automatic weather station (AWS) were deployed at the Achern site. All instruments were set up to run continuously from $13^{\text {th }}$ June to $16^{\text {th }}$ August 2007. The lidar, built by Halo Photonics, was deployed and, being autonomous, was left unattended and fully controlled over the internet. It had been previously deployed during the World Weather Research Project (WWRP) Helsinki Testbed (BOZIER et al., 2007).

The Salford Autonomous Doppler Lidar System, operating at a wavelength of $1.5 \mu \mathrm{m}$, employs novel fibre optic technology and the design approach has led to a new type of eye-safe Doppler lidar providing a high level of performance and exhibiting exceptional stability, which was demonstrated by this successful deployment. A detailed analysis of wind measurements pre- 

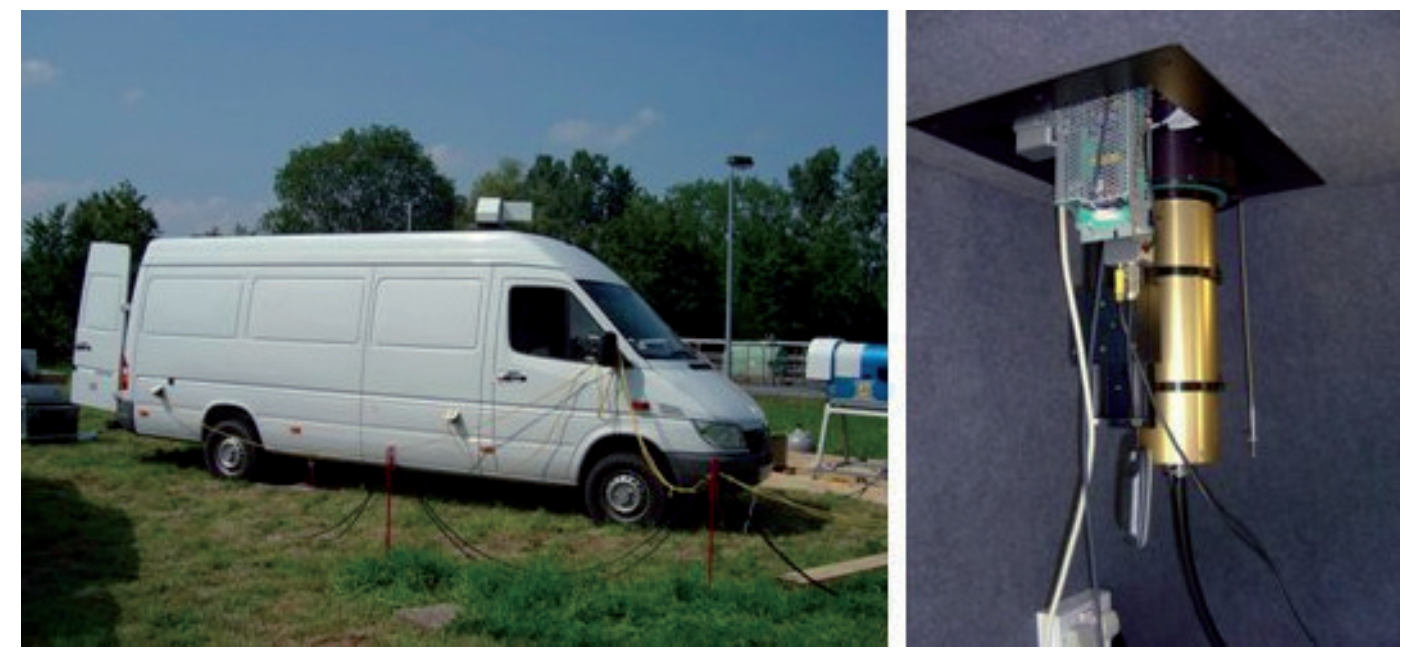

Figure 1: The Salford University Doppler lidar with antenna (inset).

Table 1: Autonomous Doppler lidar system parameters.

\begin{tabular}{ll}
\hline Parameter & Value \\
\hline Operating Wavelength & $1.5 \mu \mathrm{m}$ \\
Pulse Repetition Frequency & $20 \mathrm{kHz}$ \\
Energy per pulse. & $10 \mu \mathrm{J}$ \\
Pulse duration & $150 \mathrm{~ns}$ \\
Beam divergence & $50 \mu \mathrm{rad}$ \\
Range gate length & $30 \mathrm{~m}$ \\
Lens diameter & $75 \mathrm{~mm}$ \\
Focal length & Infinity \\
Minimum range & $100 \mathrm{~m}$ \\
Maximum Range & $7 \mathrm{~km}$ \\
Temporal resolution & $0.1-30 \mathrm{~s}$ \\
\hline
\end{tabular}

viously made with this lidar system has been given in PEARSON et al. (2009). Figure 1 illustrates the University of Salford Doppler lidar system in position at the COPS field site in Achern, Germany.

The Doppler lidar data was selected to test a methodology discussed in depth by DAVIS et al. (2008) and GAL-CHEN et al. (1992) for calculating $Q_{H}$, in an urban area. This involves using an estimation of the kinetic energy dissipation and the vertical gradient of the third moment of the vertical velocity. During the COPS field trial, there were few instruments measuring $Q_{H}$, and none of these were located at the Achern site. However, the conditions and scanning strategy employed meant that the data were suitable for testing this methodology in a semi-rural area, and since $Q_{H}$ is an important variable when investigating the development of thermals (THIELEN et al., 2000) and associated rainfall (BENNETT et al., 2006; RozOFF et al., 2003), the COPS field trial was considered an good opportunity for this methodology to be tested.

\section{The Salford University Halo Photonics Doppler lidar}

The lidar system was developed to meet the requirements of the University of Salford, being capable of unattended, autonomous operation. The University of Salford specification required a Doppler lidar system capable of providing high temporal and spatial resolution measurements of the wind velocity and backscatter within the atmospheric boundary layer. The system is portable and rugged and capable of being used for field work and long term measurements (BOZIER et al., 2007; PEARSON et al., 2009). The lidar works by transmitting a short laser pulse, of approximately $1 \times 10^{-7} \mathrm{~s}$, and collecting the backscattered signal from the illuminated aerosol targets along the path of the laser beam - see Table 1 for more details of the lidar. The primary scatterers are small atmospheric aerosol particles whose diameters are within an order of magnitude of the lidar wavelength. At optical wavelengths, scattering within the lower atmosphere is primarily by particles with diameters less than $3 \mu \mathrm{m}$, which are sufficiently small to be advected by the wind, and serve as an effective tracer of wind velocity (DAVIES et al., 2003; HARDESTY et al., 1992); FRELICH, 1995; SCHWIESOW, 1986). Accurate estimates of the radial component of the velocity (along the line of sight of the laser beam) are produced as a spatial average over the sensing volume of the transmitted pulse.

The lidar system has a modular design arranged in three separate units; the optical base unit, the weatherproof antenna, consisting of the telescope and associated commercially sensitive, scanning electronics, and the signal processing and data acquisition unit. The base unit has approximate dimensions $56 \mathrm{~cm}$ x $54 \mathrm{~cm}$ x $18 \mathrm{~cm}$ and contains the optical source, interferometer, receiver and the electronics. The weather-proof antenna is attached to the base unit via a 1 " diameter, $1 \mathrm{~m}$ long optical fibre conduit. The antenna can be deployed permanently 


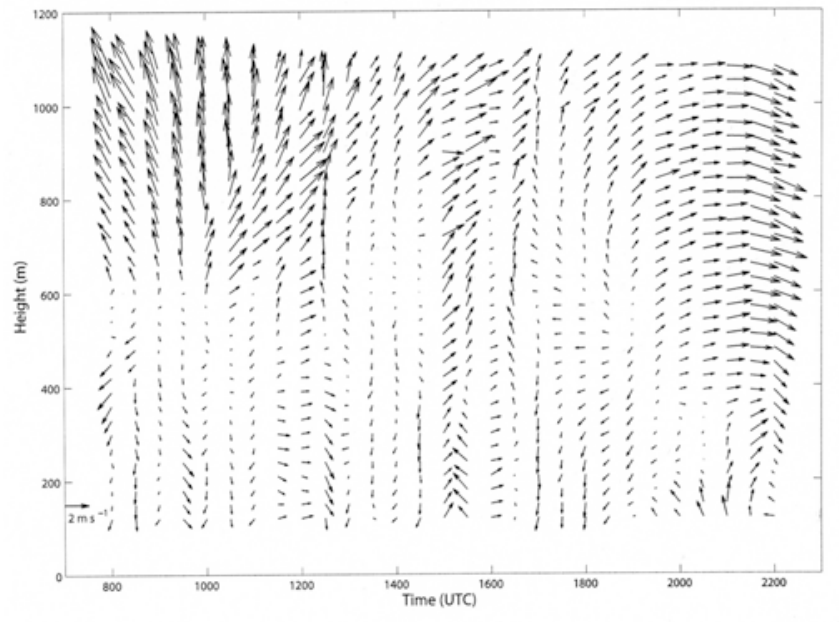

Figure 2: Wind vector plot for 15/07/07, 0800-2200 h UTC, arrows represent relative horizontal wind speed and direction. Due to some wind velocities being very small, the arrows appear as dots. The legend (bottom left) shows an arrow representing a $2 \mathrm{~m} \mathrm{~s}^{-1}$ wind speed, with westerly direction.

outside whilst the base unit and data acquisition system are housed within a mobile laboratory environment. The signal processing has been developed with a view to providing a high level of flexibility with respect to the data acquisition parameters. Users are able to set parameters such as the range gate length, maximum range and number of pulses accumulated for each measurement, as detailed in Table 1. During the field campaign, measurements were limited only by atmospheric moisture (rain/fog), a lightning strike and a mains power failure. The Doppler lidar system is described in greater detail in PEARSON et al. (2009), HALO Photonics $\left(2008^{2}\right)$.

\section{Measurements}

The UFAM pulsed Doppler lidar is capable of measuring:

- Directly: Radial wind velocity, relative backscatter intensity

- Indirectly: Horizontal velocities, their variances and covariances, atmospheric backscatter coefficient $(\beta)$ and turbulence kinetic energy dissipation rate $(\varepsilon)$

During much of the field campaign, the lidar system performed a series of scan patterns pre-programmed into the system software. Errors are given in Table 1 and described in more detail in PEARSON et al. (2009). Generally, the system carried out:

- 5 minute azimuth scan at 5 different elevations $\left(20^{\circ}\right.$, $30^{\circ}, 40^{\circ}, 45^{\circ}$ and $60^{\circ}$ ), but on the case discussed here, azimuth scans were performed at $60^{\circ}$

${ }^{2}$ The Halo Photonics pulsed Doppler LiDAR system, available at www.halophotonics.com

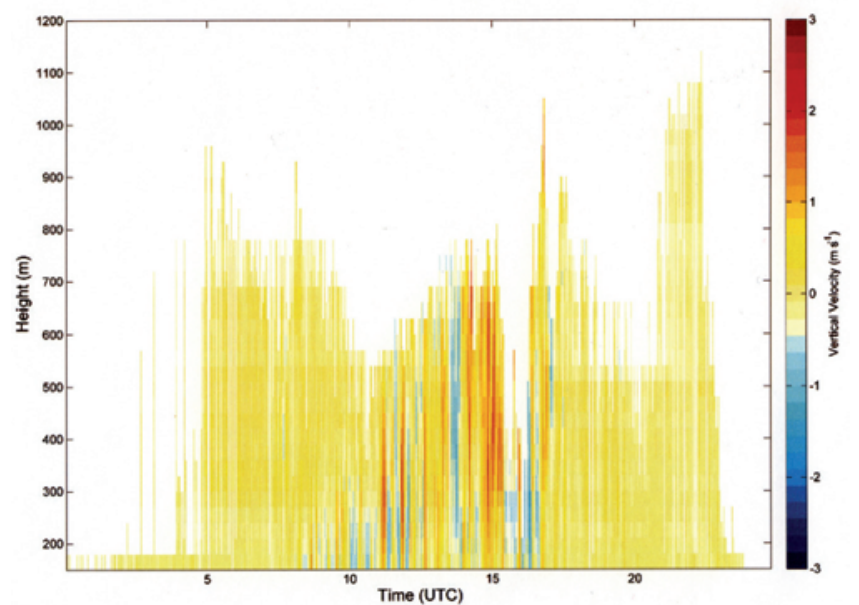

Figure 3: Full day view, 15/07/07, showing thermals building throughout the day.

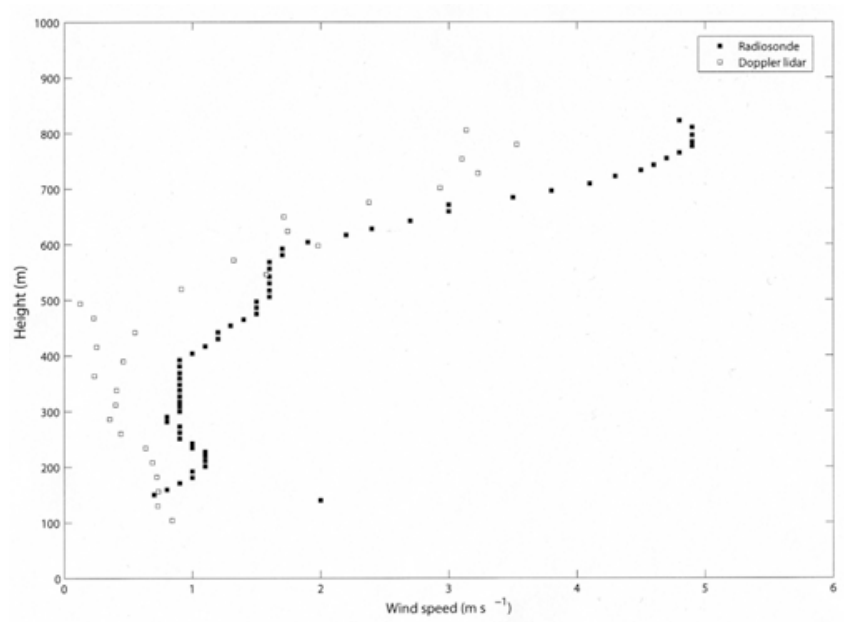

Figure 4: Doppler lidar and radiosonde horizontal wind speeds to $800 \mathrm{~m}$.

- 25 minute vertically fixed stare consisting of 334 radial velocity 'ray' measurements.

The azimuth scan was performed to determine wind velocity profiles, derived from VAD analysis (BROWNING and WEXLER, 1968) and these data were concatenated enabling a half-hourly vector profile, as illustrated in Figure 2 . The vertically pointing stares were concatenated to produce a complete overview of vertical velocities measured by the Doppler lidar each day, as illustrated in Figure 3. Both Figure 2 and Figure 3 show data up to a height of $1100 \mathrm{~m}$. Beyond this range, on this day there was no signal return. The data illustrated can be used to calculate a variety of products, including mixed layer height (COLLIER et al., 2005; MOK and RUDOWICZ, 2004) and turbulence statistics DAVIES et al. (2004), LENSCHOW et al. (2000), FRELICH and CORNMAN (2002) and BANAKH et al. (1999).

The data from the $15^{\text {th }}$ July 2007 show that thermals were building throughout the day and the synoptic situa- 
tion indicated that a convergence line passed, from west to east, to the north of Achern. High convectivity, particularly at around 1500 UTC, was measured by the lidar. The convective conditions suggested a suitable day to use lidar data to calculate $\left(Q_{H}\right)$, a parameter important in monitoring the development of thermals. A method discussed in detail by DAVIS et al. (2008) is outlined and tested here.

It was first necessary to confirm the reliability of the Doppler lidar data. Comparisons were made between horizontal velocity data measured by the lidar, radiosonde and a $1290 \mathrm{MHz}$ wind profiler and are shown here.

Figure 4 illustrates similarities between horizontal velocities measured by Doppler lidar and radiosonde: the radiosonde was launched at 1000 UTC and the azimuth scan was performed from 1000 UTC to 1005 UTC. When this data was taken it is considered that the boundary layer top was at around $800 \mathrm{~m}$, and the lidar data becomes noisy, and therefore un-useable, above this level.

Another comparison was made between the UFAM Doppler lidar data and the University of Manchester operated, UFAM funded $1290 \mathrm{MHz}$ wind profiler. This is illustrated in Figure 5. As with the radiosonde data (Figure 4), it can be seen that there are similarities between the two datasets. There are some areas of small scale differences, but generally the two remote sensing instruments are providing comparable data. Having established that the Doppler lidar is a suitable instrument to make atmospheric measurements, and that the ambient conditions were appropriate, more complex calculations could be performed to investigate other parameters such as $Q_{H}$.

The chosen method assumes unstable conditions, so to confirm whether this was the situation for the $15^{\text {th }}$ July 2007 case, potential temperature profiles were derived from two radiosonde ascents launched from the Achern site. These profiles, suggesting unstable conditions are shown in Figure 6.

\section{Methodology}

Having established unstable conditions, it was possible to calculate $Q_{H}$ from the vertical velocity-potential temperature covariance term $\left(\overline{w^{\prime} \theta^{\prime}}\right)$ in (4.1) following the procedure outlined in GAL-CHEN et al. (1992):

$$
\frac{g}{\theta_{0}} \overline{w^{\prime} \theta^{\prime}}=\frac{1}{\rho_{0}} \overline{w^{\prime} \frac{\partial p^{\prime}}{\partial z}}+\frac{\varepsilon}{3}+\frac{\partial}{\partial z}\left(\frac{1}{2} \overline{w^{\prime 3}}\right)
$$

WYNGAARD and CoTÉ (1971) and DAVIS et al. (2008) found that the pressure term, $\frac{\partial p^{\prime}}{\partial z}$, was small compared with the other terms of (4.2) for unstable conditions and will therefore be ignored in the subsequent analysis, which can be applied only to cases of convection, hence:

$$
\overline{w^{\prime} \theta^{\prime}} \approx \frac{\theta_{0}}{g}\left[\frac{\partial}{\partial z}\left(\frac{1}{2} \overline{w^{\prime 3}}\right)+\frac{\varepsilon}{3}\right]
$$

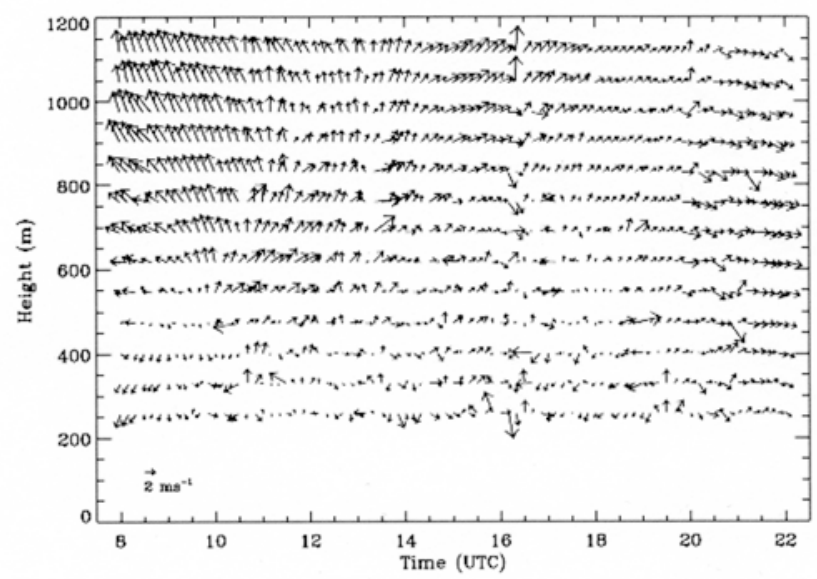

Figure 5: Vector plot from UFAM $1290 \mathrm{MHz}$ wind profiler showing similar features to the lidar (Figure 2), with easterlies early in the morning, becoming southerly as the morning progresses and veering westerly in the afternoon.

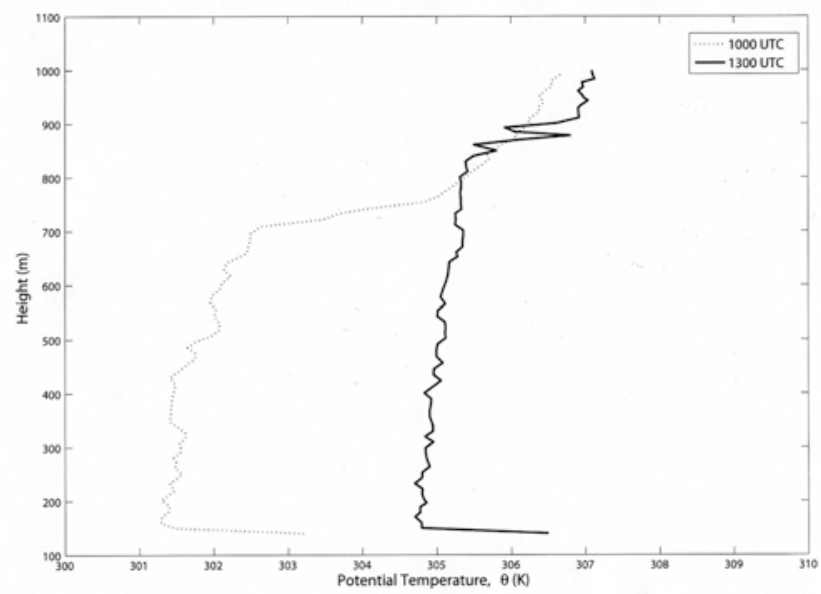

Figure 6: Potential temperature profiles on 15/07/07 suggesting unstable conditions.

The mean vertical velocity, $\bar{w}$, is calculated for each range gate and averaged over the 25 minute scan period. This is done for each of the nineteen $30 \mathrm{~m}$-long range gates, from $135 \mathrm{~m}$ to $705 \mathrm{~m}$, using data from a vertically pointing stare scan. The w' is the deviation from the mean vertical velocity. Then, $\mathrm{w}^{3}$ is calculated for each point and averaged over the 25 minute scan duration to form a profile of $\overline{w^{\prime 3}}$.

In order to use (4.2) to calculate $\overline{w^{\prime} \theta^{\prime}}$, it is also necessary to estimate $\varepsilon$. One way of estimating $\varepsilon$ is to examine the line spectra of the longitudinal velocity correlation. In the inertial subrange, the expected relationship is (BATCHELOR, 1967):

$$
\bar{f}(\kappa)=\alpha \varepsilon^{2 / 3} \kappa^{-5 / 3}
$$

where $\kappa$ is the wave number, $\alpha$ is a universal constant $(0.5)$ and $\bar{f}(\kappa)$ is the Fourier transform of the longitudinal velocity correlation. A $-5 / 3$ slope indicates the pres- 
Table 2: Errors associated with Doppler lidar calculations of $\varepsilon$ and $\overline{w^{\prime 2}}$.

\begin{tabular}{lll}
\hline Error type and extent & & \\
\hline Vertical velocity variance, $\overline{w^{\prime 2}}$ & $\begin{array}{l}\text { Bias }=0.02 \mathrm{~m}^{2} \mathrm{~s}^{-2} \\
\text { Random }= \pm 0.68 \mathrm{~m}^{2} \mathrm{~s}^{-2}\end{array}$ & PEARson et al., 2008 \\
$\begin{array}{l}\text { Turbulent kinetic energy } \\
\text { dissipation rate, } \varepsilon\end{array}$ & Error $=10 \%$ & FRELICH and CoRnMAN, 2002 \\
\hline
\end{tabular}

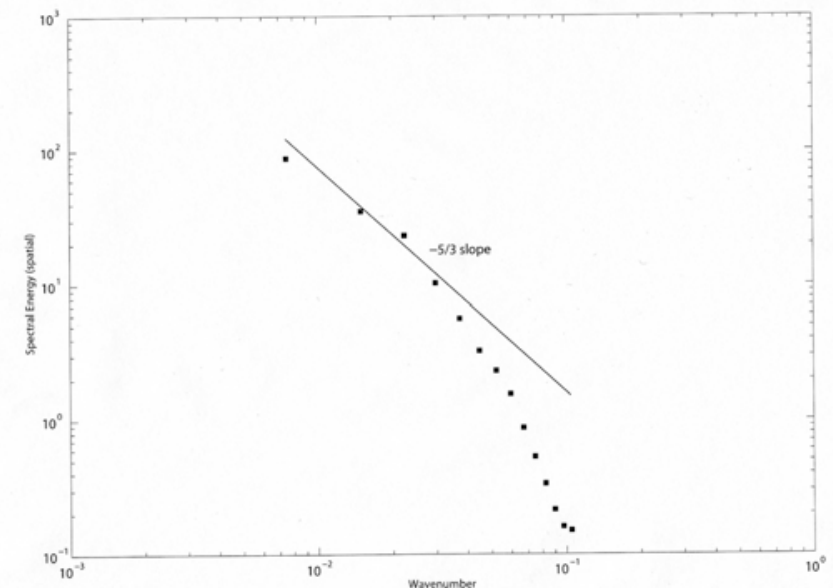

Figure 7: Spectrum from the GAL-CHEN et al. (1992) spatial method. A $-5 / 3$ gradient indicates the presence of the inertial subrange.

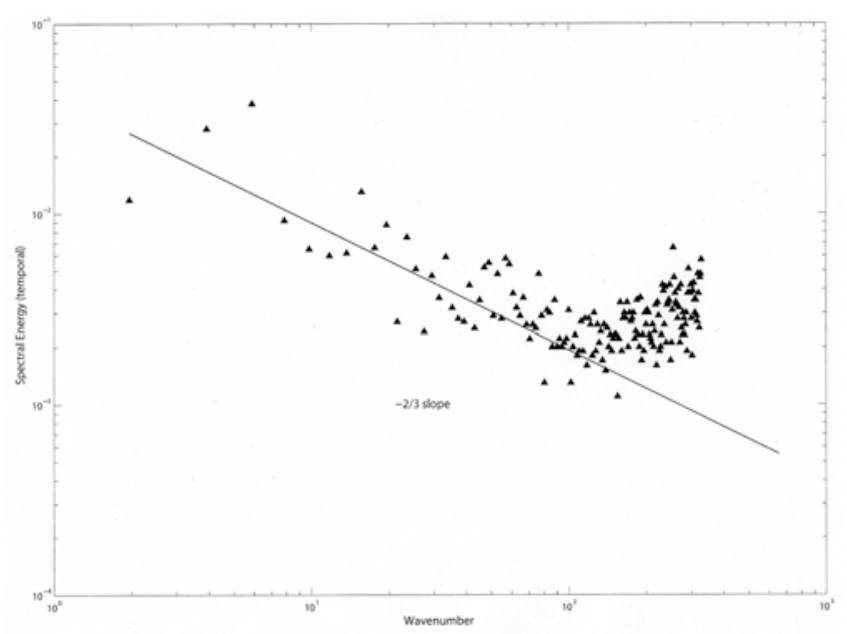

Figure 8: Temporal spectrum as reported by CHAMPAGNE et al. (1977). The $-2 / 3$ slope highlights the presence of the inertial subrange.

ence of an inertial subrange and is shown in Figure 7. This will be referred to henceforth as the spatial spectra method. We calculate the spectra for each ray from 135 to $705 \mathrm{~m}$ and average the spectra over the 25 minute time period.

An alternative method for calculating spectra is proposed by CHAMPAGNE et al. (1977). Here, Taylor's Hy- pothesis (STULL, 1988) is assumed and is used to calculate the wave number. The $\bar{u}$ is calculated from the lidar data using VAD analysis. The $\bar{u}$ is the average mean wind over the 135-705 $\mathrm{m}$ height range. The spectrum can be calculated from:

$$
n S(n)=0.68 \varepsilon^{2 / 3}\left(\frac{2 \pi n}{\bar{u}}\right)^{-2 / 3}
$$

where $S(n)$ is the spectral energy of frequency $n$ and $\bar{u}$ is the mean wind speed. Here, the inertial subrange is characterized by a $-2 / 3$ gradient and is shown in Figure 8 . This will be referred to henceforth as the temporal spectra method.

When performing spectral analysis to obtain $\varepsilon$, the data were detrended to remove any nonstationary behaviour. However, errors are still expected, and these are listed in Table 2.

With unstable conditions, $Q_{H}$ can thus be calculated from:

$$
Q_{H}=\rho_{0} C_{P} \overline{w^{\prime} \theta^{\prime}}
$$

taking $C_{P}$, the heat capacity of air at constant pressure, as $1004 \mathrm{~J} \mathrm{k}^{-1} \mathrm{~kg}^{-1} \mathrm{~K}-1, \rho_{0}$, the air density, as 1.275 $\mathrm{kg} \mathrm{m}^{-3}$ and where is the potential temperature-vertical velocity covariance calculated in (4.2) (GAL-CHEN et al., 1992). (4.3) also assumes unstable conditions, which were present on this day as illustrated in Figure 6.

\section{Results}

The Salford Autonomous Doppler Lidar System was deployed for COPS in Achern, Germany, where it collected data almost continuously for 3 months. A case study of convective development is described here and the results include turbulence spectra and some timeseries of $\varepsilon$ and $Q_{H}$. Figure 7 shows a spectrum produced from a vertically-pointing stare taken at 1100 UTC on the $15^{\text {th }}$ July 2007 in order to obtain a single value of $\varepsilon$. The spectrum in Figure 7 was calculated using the spatial method presented by GAL-CHEN et al. (1992). In addition, in order to confirm the results shown in Figure 7 , spectra were also plotted using the same dataset and the method proposed by CHAMPAGNE et al. (1977) as shown in Figure 8. The points deviating from the expected $-2 / 3$ gradient at high wavenumbers are considered to be due to noise (MAYOR et al., 1997). 


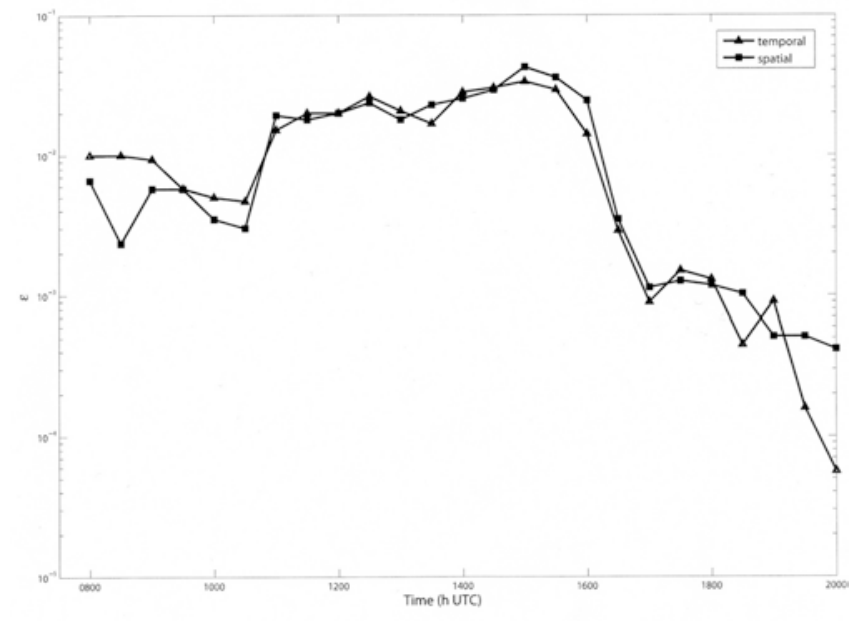

Figure 9: Eddy dissipation rates calculated from Doppler lidar data using both spatial and temporal methods on 15/07/07.

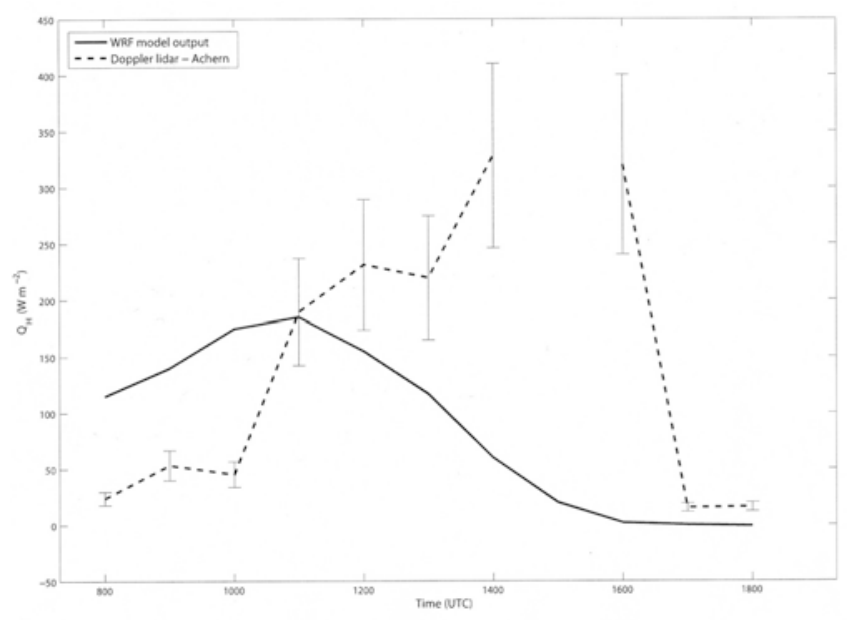

Figure 10: $Q_{H}$ timeseries calculated for 15/07/07, showing an estimation of the expected errors. Half-hourly averages of $Q_{H}$, as measured by the IMK-FZK energy balance station for that day are also shown.

The time series in Figure 9 illustrates $\varepsilon$, derived from both temporal and spatial methods, developing throughout the day as would be expected - increasing towards noon, peaking at $1500 \mathrm{UTC}$ and then decreasing towards the evening, as convection is developing in the morning and then dissipating in the evening (STULL, 1988). With the estimates for $\varepsilon$ and vertical velocity fluctuations $\left(w^{\prime 3}\right), Q_{H}$ was calculated, as illustrated in Figure 10. It was decided that although the $\varepsilon$ values were similar for both spectra, the values derived from the spatial spectra would be utilised to calculate $Q_{H}$ as per GALCHEN et al. (1992). Figure 10 also shows a timeseries of $Q_{H}$, measured using an Energy Balance Station at the COPS operation centre, Baden Airpark, $10 \mathrm{~km}$ north of Achern where the Doppler lidar was located, but still in the Rhine Valley.

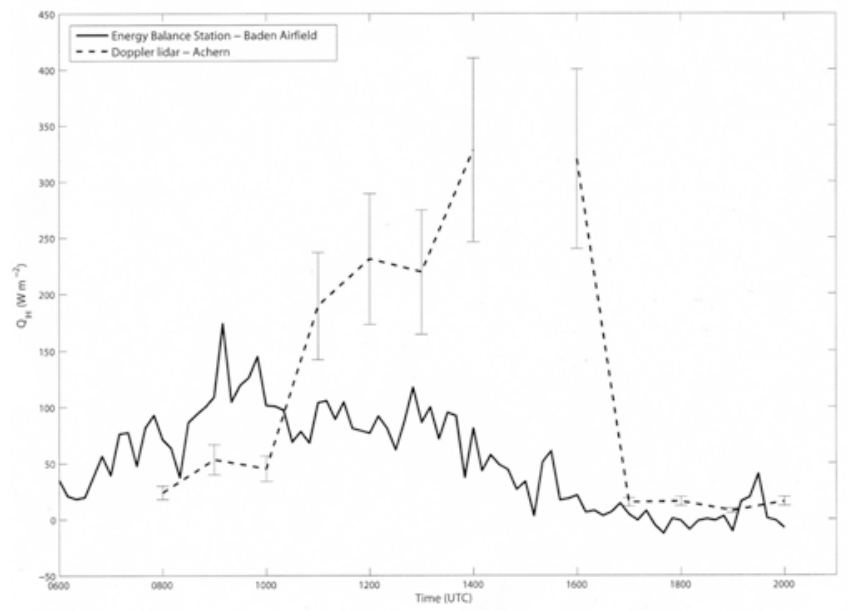

Figure 11: $Q_{H}$ from Doppler lidar data and WRF model data.

When considering the results achieved using the data collected with the Doppler lidar, certain factors need to be considered, for example, how did the results compare with other measurements? Figure 10 shows the lidar data plotted against data collected from an energy balance station, located at Baden Airpark, $10 \mathrm{~km}$ to the north of the Doppler lidar. The energy balance station made point measurements of $Q_{H}$, at a single point in time, at the surface and averaged over half an hour. The measurements made by the lidar are averages over the depth of the boundary layer up to $705 \mathrm{~m}$ and while showing a general trend, cannot be the same for the following reasons:

- The two instruments were not collocated;

- The lidar, as a remote sensor, provides a volume average over a pencil-shaped beam, over a range of $120 \mathrm{~m}$ to $705 \mathrm{~m}$ above the surface.

The $Q_{H}$ values measured by the lidar are higher than those measured at Baden Airpark. It is considered that the relatively high values of $Q_{H}$ calculated from the lidar data compared with those from the energy balance station result from the nature of the instruments and their associated 'footprints' (SCHMID, 1994). Lidar measurements are averaged over the lowest $\sim 700$ $\mathrm{m}$ of the boundary layer and so have larger footprints than ground based instruments, in the order of several kilometres. WOOD and MASON (1993); BELCHER and WOOD (1996) and WOOD et al. (2001) discuss the effects of increasing form drag and roughness length when flow is directed across orography such as the mountains to the east of the Achern site. Since the mountains are some $8 \mathrm{~km}$ away, within the fetch of the lidar it is considered that it the high eddy dissipation rates are due to this orography. These high values greatly influence the magnitude of the $Q_{H}$. The instruments at Baden Airpark are at surface level so have lower fetch and are unlikely to be affected by the orography. It should also be 
noted that, on this occasion, the synoptic situation indicated that the convergence line mentioned in section 3 was more active to the north of Achern.

Despite these differences, the results are comparable, having a reasonable order of magnitude and showing a diurnal trend as expected.

Output from the NERC WRF model runs for this day is shown in Figure 11. These data also show a diurnal trend, similar to those shown in Figure 10. It is not realistic to expect remotely sensed data to replicate the results from a computer model, but as with the surface values, the results are within the same order of magnitude, there is a similar trend in the model output, with values rising towards noon and dropping towards sunset. It is interesting to note that where the model output suggests high heat flux values at 0800 UTC, the lidar does not. Although the measured $Q_{H}$ values were comparatively high, at around 1500 UTC these values were unrealistically so. It is thought that this may be due to a mesoscale event that occurred at about 1500 UTC that day as mentioned previously. Investigations into this are ongoing.

\section{Conclusions and future work}

It has been shown that by using a method outlined by DAVIS et al. (2008), GAL-CHEN et al. (1992), it is possible to calculate values of $Q_{H}$ and it is considered that these values fall within an acceptable range. It is noted that the diurnal cycle of the lidar-derived $Q_{H}$ is closer to the diurnal cycle of $\varepsilon$, whereas both the model and surface measurements of $Q_{H}$ peak earlier in the day. $Q_{H}$ calculated from Doppler lidar data using the method described here would be expected to differ from that calculated using a surface based 'point' sensor such as an energy balance instrument or a sonic anemometer; since the data collected with a Doppler lidar is integrated over a 'volume' of atmosphere aloft, advecting through the laser beam. However, these measurements are a useful addition to the other measurements provided by the lidar, and require no extra equipment.

It is considered that further investigations of employing this method to calculate $Q_{H}$ are needed to establish the overall applicability of the method and build on the preliminary calculations. It is expected that such investigations will include:

- Calculation of $\varepsilon$ using alternative methods;

- investigation of $\varepsilon$ at different heights and atmospheric conditions;

- verification of Doppler lidar estimations of $\varepsilon$ and $w^{\prime 3}$; and

- investigation over different surface types.

\section{Acknowledgments}

The authors would like to acknowledge Dr. N. KALTHOFF at IMK FZK Karlsruhe for supplying $Q_{H}$ data from their energy balance station located at Baden Airfield, Germany, collected as part of COPS, July 2007. Also Dr. A. GADIAN from the University of Leeds, for his help in securing the WRF model output; Dr. E. NORTON from the University of Manchester, for making the UFAM $1290 \mathrm{MHz}$ wind profiler quicklook plots available online; H.P. SCHMID for the use of the flux sourcearea model (FSAM); finally, UK COPS, for funding through NERC.

\section{References}

BANAKh, V.A., I.N. Smalikho, F. Kopp, C. Werner, 1999: Measurements of turbulent energy dissipation rate with a CW Doppler lidar in the atmospheric boundary layer. J. Atmos. Oceanic Technol. 16, $1044-1061$.

BATCHELOR, G.K., 1967: The theory of homogeneous turbulence, 5th ed. - Cambridge University Press, London.

Belcher, S.E., A. Wood, 1996: Form and wave drag due to stably stratified turbulent flow over low ridges. - Quart. J. Roy. Meteor. Soc. 122, 863-902.

Bennett, L.J., K.A. Browning, A.M. Blyth, D.J. PARKER, P.A. CLARK, 2006: A review of the initiation of precipitating convection in the United Kingdom. - Quart. J. Roy. Meteor. Soc. 132, 1001-1020.

Bozier, K.E., G.N. Pearson, C.G. Collier, 2007: Doppler lidar observations of Russian forest fire plumes over Helsinki. - Weather 62, 203-208.

Browning, K.A., R. WeXleR, 1968: The Determination of Kinematic Properties of a Wind Field using Doppler Radar. - Quart. J. Roy. Meteor. Soc. 97, 283-299.

Champagne, F.H., C.A. Friehe, J.C. LARUe, J.C. WynGAARD, 1977: Flux measurements, flux estimation techniques and fine scale turbulence measurements in the unstable surface layer over land. - J. Atmos. Sci. 34, 515530 .

Collier, C.G., F. Davies, K.E. Bozier, A.R. Holt, D.R. Middleton, G.N. Pearson, S. Siemen, D.V. Willets, G.J.G. Upton, R.I. Young, 2005: Dual Doppler lidar measurements for improving dispersion models. - Bull. Amer. Meter. Soc. 86, 825-838.

Davies, F., C.G. Collier,K.E. Bozier, G.N. Pearson, 2003: On the accuracy of retrieved wind information from Doppler lidar observations. - Quart. J. Roy. Meteor. Soc. 129, 321-334.

Davies, F., C.G. Collier, G.N. Pearson, K.E. Bozier, 2004: Doppler lidar measurements of turbulent structure function over an urban area. - J. Atmos. Oceanic Technol. 21, 753-761.

Davis, J.C., K.E. Bozier, C.G. Collier, F. Davies, 2008: Spatial variations of sensible heat flux over an urban area. - Meteor. Appl. 15, 367-380.

FREHLICH, R.G., 1995: Comparison of 2- and 10- $\mu \mathrm{m}$ coherent Doppler lidar performance. - J. Atmos. Oceanic Technol. 14, 54-75.

FREHLICH, R., L. CORNMAN, 2002: Estimating spatial velocity statistics with coherent Doppler lidar. - J. Atmos. Oceanic Technol. 19, 355-366. 
Gal-Chen, T., M. Xu, W.L. Eberhard, 1992: Estimations of atmospheric boundary layer fluxes and other turbulence parameters from Doppler lidar data. - J. Geophys. Res. 97, D17 18409-18423.

Hardesty, R.M., C.J. Grund, M.J. Post, B.J. Rye, G.N. PEARSON, 1992: Measurements of winds and cloud characteristics: a comparison of Doppler lidar systems. Paper 2, Session TA-P. - International Geoscience and Remote Sensing Symposium, Houston, Texas, USA.

LEnschow, D.H., V. WulfMEyer, C. SEnFF, 2000: Measuring Second- through Fourth-Order Moments in Noisy Data. - J. Atmos. Oceanic Technol. 17, 1330-1347.

MAYOR, S.D., S.A. COHN, D.H. LENSCHOW, C.J. Grund, R.M. HaRdesty, 1997: Convective Boundary Layer Vertical Velocity Statistics Observed by $2-\mu \mathrm{m}$ Doppler Lidar. $-9^{\text {th }}$ Conference on Coherent Laser Radar, June 23-27, Linköping, Sweden.

Mok, T.M., C.Z. Rudowicz, 2004: A lidar study of the atmospheric entrainment zone and mixed layer over Hong Kong. - Atmos. Res. 69, 147-163.

Pearson, G., F. Davies, C. Collier,, 2009: An analysis of the performance of the UFAM pulsed Doppler lidar for observing the boundary layer. - J. Atmos. Oceanic Technol. 2, 240-250.

Rozoff, C.M., W.R. Cotton, J.O. Adegoke, 2003: Simulation of St. Louis, Missouri, Land Use Impacts on Thun- derstorms. - J. Appl. Meteor. 42, 716-738.

SCHMID, H.P., 1994: Source areas for scalars and scalar fluxes. - Bound.-Layer Meteor. 67, 293-318.

SCHWIESOW, R.L., 1986: A comparative overview of active remote-sensing techniques, in Lenschow D.H. (Ed.): Probing the atmospheric boundary layer, Amer. Meteorol. Soc., Boston.

STUlL, R.B., 1988: An introduction to Boundary Layer Meteorology. - Kluwer Academic Publishers, The Netherlands.

Thielen, J., W. Wobrock, A. Gadian, P. Metstayer, J. CREUTIN, 2000: The possible influence of urban surfaces on rain fall development: a sensitivity study in 2D in the meso- $\gamma$-scale. Atmos. Res. 54, 15-39.

Wood, N., A.R. Brown, F.E. Hewer, 2001: Parametrizing the effects of orography on the boundary layer: an alternative to effective roughness lengths. - Quart. J. Roy. Meteor. Soc. 127, 759-777.

Wood, N., P.J. MASON, 1993: The pressure force induced by neutral turbulent flow over hills. - Quart .J. Roy. Meteor. Soc. 119, 1233-1267.

WYNGAARD, J.C., O.R. COTÉ, 1971: The budgets of turbulent kinetic energy and temperature variance in the atmospheric surface layer. - J. Atmos. Sci. 28, 190-201. 